\title{
A Cylindrical Linear Permanent Magnet Vernier Hybrid Machine for Wave Energy
}

\author{
Nick J. Baker, Mohammad A.H. Raihan, Ahmed A. Almoraya
}

\begin{abstract}
In some wave energy converters, there is a need for linear electrical machines where all the active parts are mounted on the stator. For this reason the linear Vernier hybrid machine has been investigated. In other research, it is analyzed in $2 \mathrm{D}$ and assumed to have a flat cross-section. In this paper a cylindrical version of the Vernier hybrid machine is presented and analyzed. A geometrical model is used to investigate potential mass savings of the cylindrical version, and a finite element analysis design study is used to demonstrate a potential improvement in performance. A proof of concept laboratory scale model has been built and tested to validate the predictions.
\end{abstract}

Index Terms-Linear generator, permanent magnet machine, Vernier hybrid machine, wave energy, cylindrical machine.

\section{NOMENCLATURE}

$\begin{array}{ll}\text { DD-WECs } & \text { Direct drive WECs. } \\ \text { FEA } & \text { Finite element analysis. } \\ \text { MMF } & \text { Magneto motive force. } \\ \text { PM } & \text { Permanent magnet. } \\ \text { VHM } & \text { Vernier hybrid machine. } \\ \text { WEC } & \text { Wave energy converter. }\end{array}$

$a$ Dimension used to scale topologies, $=w_{m}$.

$B_{\text {root }} \quad$ Flux density in root.

$B_{t} \quad$ Flux density under tooth.

$B_{0}, B_{l} \quad$ Average and fundamental flux density.

$F \quad$ Force requirement of machine.

$F_{x} \quad$ Overall thrust force.

$g \quad$ Air gap length.

$h_{s} \quad$ Height of stator.

$h_{t} \quad$ Height of translator.

$H_{c} \quad$ Coercive force of magnets.

$i_{a} \quad$ Instantenious current.

I Current.

$k \quad$ Integer.

$K \quad$ Machine constant.

$K_{G} \quad$ Machine constant power density.

$l_{a} \quad$ Axial or stack length.

$L \quad$ Active length of stator.

$m \quad$ Number of phases.

$n \quad$ Number of turns per coil.

$N \quad$ Number of translator teeth per stator tooth.

$r_{s 1}-r_{s 3} \quad$ Radius of various stator components.

$r_{t 1}, r_{t 2} \quad$ Radius of various translator components.

$R \quad$ Resistance.

This work was supported in part by the UK EPSRC under Grant EP/N021452/1. $t$

$t_{m}$

V

$w_{c}$

$w_{s t}$

$w_{m}$

$x$

$X$

$\mu_{0}$

$\mu_{r}$

$\sigma$

$\sigma_{\text {peak }}$

$\tau_{t}$

\author{
Translator tooth width. \\ Thickness of PM. \\ Volume. \\ Copper loss. \\ Width between stator teeth. \\ Width of PM. \\ Translator stroke length. \\ Ratio of stator length to stroke length. \\ Permeability of free space. \\ Relative permeability. \\ Average shear stress. \\ Peak shear stress. \\ Tooth pitch.
}

\section{INTRODUCTION}

$\mathrm{W}$ AVE energy converters have the potential to contribute low carbon electricity on a large scale over the coming decades. Many of the devices produce low speed, reciprocating motion which must be converted into electricity. High force linear permanent magnet (PM) machines may be a strong contender for direct drive power take off without the need for the mechanical linkages which are required to facilitate the use of conventional rotary electric machines.

The permanent magnet Vernier hybrid machine (VHM) is a member of the variable reluctance PM machines family which are known to exhibit high force or torque density. Reluctance variation caused by the slotted translator gives a magnetic gearing effect, which allows these machines to generate high power even at low speed [1-3]. Various authors have considered conventional rotary [4] and flat linear [5, 6] versions of this topology at laboratory scale. Equivalent circuit [7], experimental results and analytical techniques [8] have been used to investigate alternative magnet configurations [6], including flux switching variants [9] and various power factor improvements [10]. Linear PM versions tend to have a flat cross section and although the cylindrical linear version of this machine is conceptually simple, it has not been proposed in the literature.

Linear generators are used in direct drive wave energy converters (DD-WECs) as the number of moving parts required in the drive train of the converters can be reduced. The removal of the mechanical interface between the prime mover and the high speed rotary generator could contribute to a significant

N. J. Baker, is a Senior Lecturer within Newcastle University's Electrical Power Group. He is a machine designer with research projects across the automotive, aerospace and renewable energy sector; M.A. Raihan and A. A. Almoraya are working towards $\mathrm{PhD}$ degrees at Newcastle. 
improvement of the overall system efficiency [11] and a reduction of the maintenance cost. The Archimedes wave swing [12] and heaving buoys [5, 9, 13] are both examples of DD-WECs where linear generators have been effectively employed.

In [14], a linear magnetic gear was combined with a linear PM machine to form a pseudo direct drive WEC. However, the complexity of manufacturing this system is problematic due to the existence of the three airgaps, two translators and the extra length produced by the integration between magnetic gear and PM machine. Transverse flux permanent magnet machines have been proposed [15] and evaluated [16] for DD-WECs, as they can offer high shear stress density and are generally regarded as one of the most force dense variable reluctance PM machines which do not rely on high current densities. However, the three-dimensional flux paths may lead to a complex mechanical structure.

Cylindrical linear PM machines have been shown to have a higher force-to-weight ratio compared to flat topologies in some scenarios [17]. Furthermore, a cylindrical configuration may have the potential to be more suitable for wave energy converter power take off as it removes the need for the translator to resist torsional forces and dynamic sealing is likely to be less challenging.

In this paper, a cylindrical VHM is proposed as an evolution from a flat single sided E-core linear VHM. 3D FEA has been used for both the flat and cylindrical models to perform a comparison study. A basic geometric study demonstrates that active mass savings are possible by moving to the cylindrical topology for a basic design, whereas simulated results of more optimized designs show that the cylindrical variant can give a higher force to weight ratio for a fixed PM mass and MMF. A laboratory prototype is used to validate simulations.
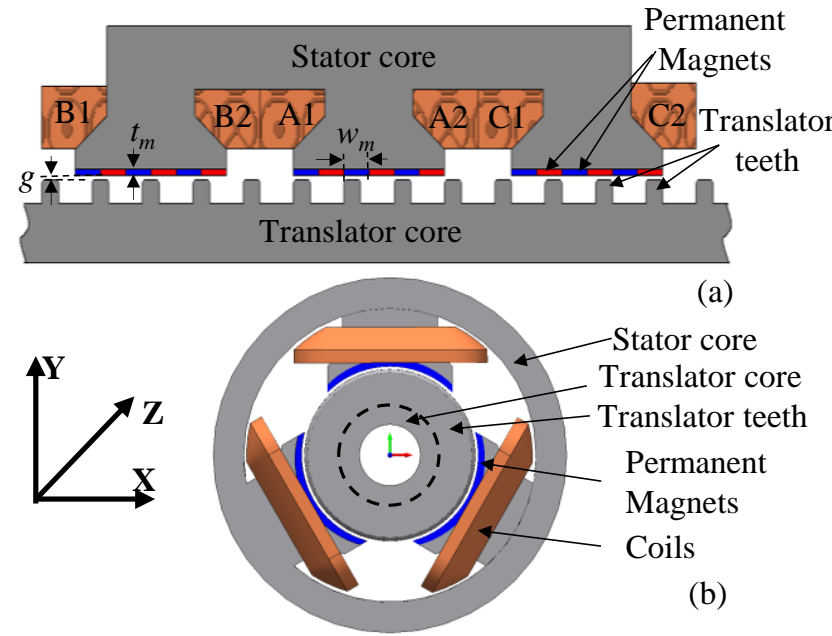

(a)

Stator core Translator core Translator teeth Permanent Magnets Coils (b)

Fig. 1. a) Flat E-core VHM b) Cylindrical VHM.

\section{THE VERNIER HYBRID MACHINE}

\section{A. Principle of operation}

A single sided E-core flat linear VHM is shown in Fig 1(a). The coils and magnets are both mounted on the stator, leaving the translator to be a purely iron, salient structure. Alignment and un-alignment between magnet poles and translator teeth produces maximum and zero flux linkage respectively. Moving the translator by a single pole pitch allows the teeth to align with the next adjacent magnets and produces reversal flux around the machine. As the translator moves a short distance, the coils see a high rate of change of flux and hence produce a high back emf, even at low speeds. The topology is hence suited to low speed, high force applications. This effect in general is called magnetic gearing and represents a non-contact method that enables direct drive machines to reach higher force density without conventional mechanical gearbox within limited size $[1,2,17]$.

\section{B. Initial design development}

Initial design dimensions of the VHM are based on a simple flux path and theoretical analysis of the equivalent reluctance network [11, 18, 19]. Maximum achievable force and the power capability of the machine can be derived from the shear stress [1]. A simple reluctance network can be derived from a single stator tooth interacting with a PM pole pair. General peak shear stress can be expressed in terms of maximum flux density under each translator tooth in (1), [3, 19].

$\sigma_{\text {peak }}=\frac{B_{t} t_{m}}{w_{m}}\left(\frac{B_{r}}{\mu_{0} \mu_{r}}\right)\left(1-\frac{g+t_{m}}{\sqrt{\left(g+t_{m}\right)^{2}+0.25 w_{m}^{2}}}\right)$

Where, $\sigma_{\text {peak }}$ is the maximum shear stress, $B_{t}$ is the flux density under the tooth, $B_{r}$ is the residual flux density of the magnet material, $\mu_{0}$ is permeability of free space, $\mu_{r}$ is the relative permeability of rare earth magnets, $g$ is the air gap length, $t_{m}$ is the magnet thickness and $w_{m}$ is the width of the magnet poles. Assuming zero leakage flux and an infinite depth of the slot, (2) [19] can be used to give an approximation that relates the flux density under the tooth $\left(B_{t}\right)$ to that at the root $\left(B_{\text {root }}\right)$.

$B_{t}=\frac{B_{\text {root }}}{1+\frac{g+t_{m}}{\sqrt{\left(g+t_{m}\right)^{2}+0.25 w_{m}^{2}}}}$

Peak thrust force occurs when the translator teeth are aligned with the intersection between adjacent magnets and the peak shear stress can be expressed by combining (1) and (2), (3).

$\sigma_{\text {peak }}=\frac{B_{r}}{\mu_{0} \mu_{r}} \frac{t_{m}}{w_{m}}\left(\frac{B_{\text {root }}}{1+\frac{\mathrm{g}+t_{m}}{\sqrt{\left(\mathrm{g}+t_{m}\right)^{2}+0.25 w_{m}^{2}}}}\right)\left(1-\frac{\mathrm{g}+t_{m}}{\sqrt{\left(\mathrm{g}+t_{m}\right)^{2}+0.25 w_{m}^{2}}}\right)$
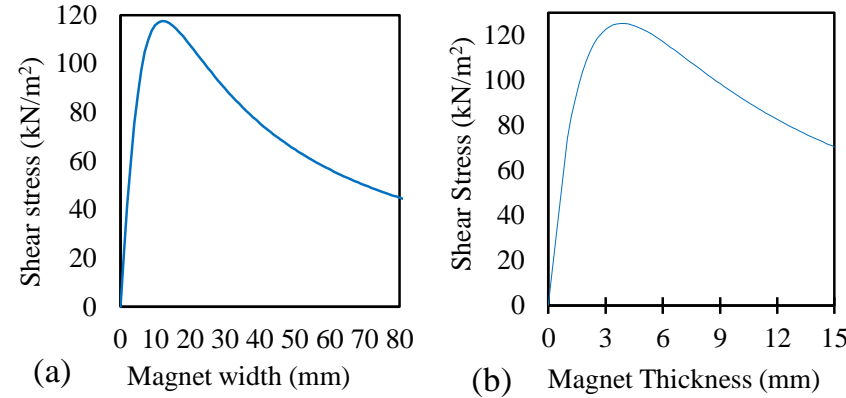

Fig. 2. Analytical analysis of magnet thickness and width for maximum shear stress for the flat VHM. (a) For a fixed magnet thickness of $4 \mathrm{~mm}$ and (b) for a fixed magnet width of $12 \mathrm{~mm}$. 
Fig. 2 uses (3) to show that for a fixed PM thickness of $4 \mathrm{~mm}$ the maximum shear stress is obtained at a magnet width of 12 $\mathrm{mm}$. Similarly, for a fixed width of $12 \mathrm{~mm}$, Fig. 2 also shows that the maximum shear stress occurs at a thickness of $4 \mathrm{~mm}$. Assumed values are $B_{r}=1.2 \mathrm{~T}, B_{\text {root }}=1.8 \mathrm{~T}$, and $g=1 \mathrm{~mm}$.

\section{Cylindrical Topology}

In this section a cylindrical version of the VHM is introduced as a logical development from the flat version, as presented in [1], for example.

Cylindrical topologies may have advantages in DD-WECs simply by merit of the smooth cross section offering a better surface for sealing than the flat (square) counterpart. In addition, the increased surface area to volume ratio makes for shorter stators. Finally, the structure is axisymmetric, and so should be able to withstand parasitic forces / torques equally well from all directions.

The flux path of the cylindrical topology is in the axial, radial and circumferential direction in both the translator and the stator. A simple laminated structure, which is well suited to the flat topology, is not appropriate in the cylinder version. It is here assumed that the entire stator and translator is made from soft magnetic composite (SMC).

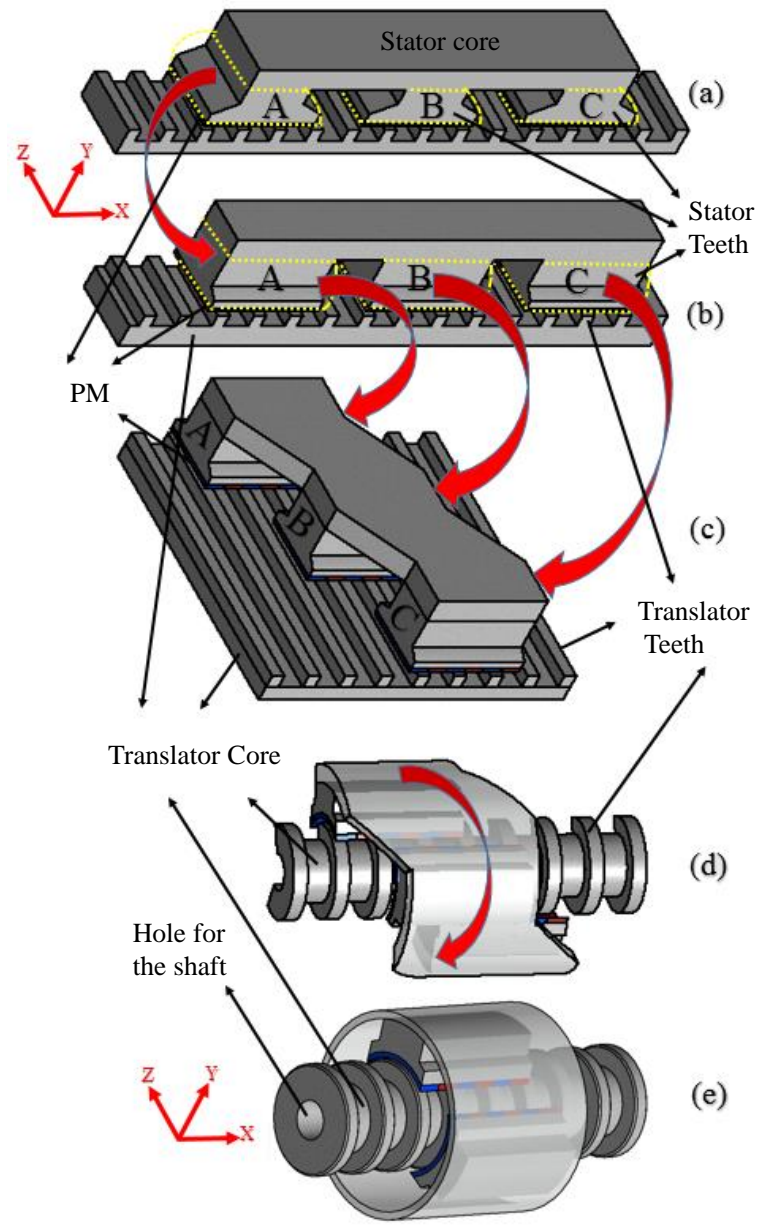

Fig. 3. The Cylindrical VHM as a development from the flat VHM.

The flat machine can be specified by its component parts: PMs, stator teeth, stator core, coils, translator teeth and translator core. Conceptually, the cylindrical version can be created from its linear counterpart shown in Fig 3(a) by the following steps:

1. Rotating stator teeth by $90^{\circ}$ around the axis of PM's magnetization (Y-axis), Fig. 3 (b).

2. Extruding the translator teeth along the axial length (Z-axis) and moving the stator tooth-B and stator tooth-C to be almost aligned with tooth A. To achieve a 120 electrical degree phase difference between stator teeth, they must be offset in the X direction, Fig. 3(c), by a function of the tooth pitch $\tau_{t}(4)$

$W_{s t}=\tau_{t}\left(k-\frac{2}{3}\right) ; \mathrm{k}=1,2,3 \ldots$.

3. The entire machine is now wrapped around the axis of motion (X-axis) - with a center through the translator core, Fig. 3(d).

4. The translator core can be hollowed out and the stator core forms a cylindrical shell enclosing all three stator teeth as shown in Fig. 3(e).

The basic operation of the cylindrical design is identical to the flat counterpart. The alignment and un-alignment of PM and translator teeth drives flux around the stator and translator. In the cylindrical model, however, all three phases link through the same translator teeth, as the translator flux path is now circumferential and parallel to the teeth, rather than perpendicular to the teeth in the original flat version. The translator core caries just a small amount of flux related to the shift between stator teeth, $W_{s t}$ in (4). The volume of the translator core can therefore be minimized for the cylindrical model.

\section{SimplifiEd GEOMETRICAL ANALYSIS}

This section presents a general geometric comparison between flat and cylindrical versions of the VHM in order to perform a basic mass comparison of the two topologies. The tooth-width is assumed to be equal to the magnet width $w_{m}$ and set to a variable $a$, which is used to scale the other dimensions based on a simplified flux flow. The active area, coil conductor area and magnet mass is set as equal in the flat and cylindrical versions.

\section{A. Flat}

Area of 1 per unit flux (maximum)

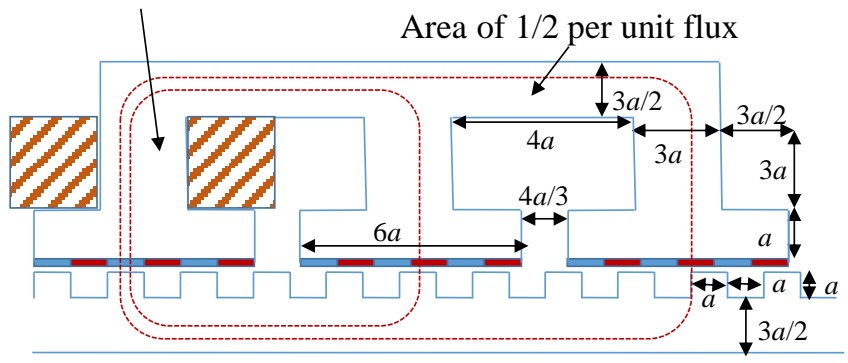

Fig. 4. Simple geometry of flat VHM used to build simple mass model

Fig. 4 shows the flat version of the VHM. The left hand stator tooth is in the aligned position and, ignoring leakage flux, must 
have a thickness of $3 a$ to carry flux from the 3 translator teeth it encompasses. For simplicity, the stator slot depth is also set to $3 a$. In reality, significant leakage occurs between the magnets, see for example [11] or Fig. 11(a) later. In recognition of this, in order to present a low mass design, the stator coreback and translator core-back are set to half this value, $3 a / 2$. Using (4), the gap between stator teeth is set to $4 a / 3$.

It is easily shown that the length of the stator core-back is $53 a / 3$ and the stator slot width would be $13 a / 3$. The conductor area per coil is $13 a^{2} / 2$ and the active area is $18 a l_{a}$, where $l_{a}$ is the active length into the plane of the figure.

\section{B. Cylindrical}

The cross sectional areas of the stator teeth of the two machines is shown to be equal in Fig. 5. The stator teeth in the cylindrical machine is seen to have a width of $l_{a} / 2$.

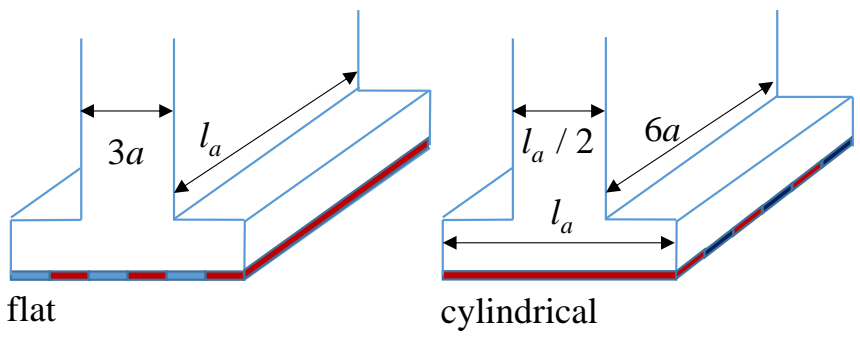

Fig. 5. Equivalence of tooth area between cylindrical and flat topologies

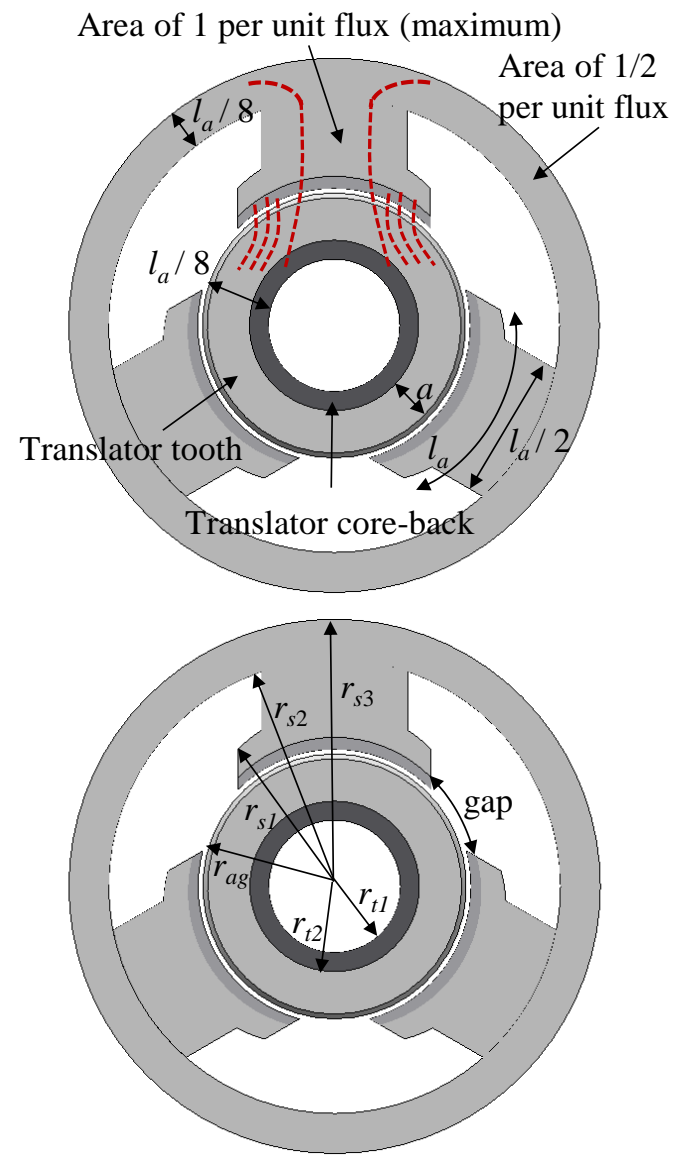

Fig. 6. Simple geometry of cylindrical VHM used to build simple mass model
In Fig. 6 the assumed flux path is shown for full alignment in the upper stator tooth. In the cylindrical machine the stator core-back and translator core-back take half the flux in each direction as the flux path splits at the stator tooth root implying a required stator core-back of half the stator tooth width, $l_{a} / 4$. To be consistent with the assumptions used in the flat geometry, the stator core-back depth is halved to account for leakage, i.e. $l_{a} / 8$. Similarly the depth of the combined translator tooth and core-back is set to $\left(l_{a} / 8\right)$. The translator slot depth is assumed to be $a$, as for the flat machine.

Each of the three stator teeth in Fig. 6 is allocated $120^{\circ}$ (mechanical), assumed to be $90^{\circ}$ active and a $30^{\circ}$ space between teeth. Equation (5) thus fixes the radius of the airgap, $r_{a g}$, such that the magnet mass between the two versions is constant.

$r_{a g}=\frac{2 l_{a}}{\pi}$

Ignoring the air gap length, which is assumed small compared to $r_{a g}$, the other radii labelled in Fig. 6(b) are defined in Table I.

\begin{tabular}{cc} 
TABLE I: DEFINITION OF RADII IN CYLINDRICAL MACHINE \\
\hline symbol & definition \\
\hline$r_{s 1}$ & $r_{a g}+a$ \\
$r_{s 2}$ & $r_{s}+3 a$ \\
$r_{s 3}$ & $r_{s 2}+l_{a} / 4$ \\
$r_{t 1}$ & $r_{a g}-l_{a} / 2$ \\
$r_{t 2}$ & $r_{a g}-a$ \\
\hline \hline
\end{tabular}

Initial 3D FEA can be used to give some confidence in the assumed flux path and assumptions about flux density. For example, Fig. 7 shows no-load flux density in the stator coreback for the two versions is equal.

(a)

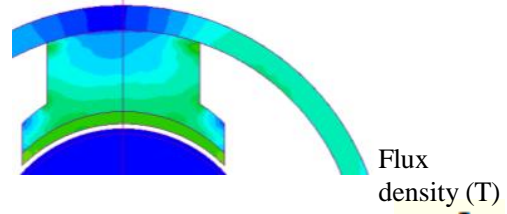

(b)

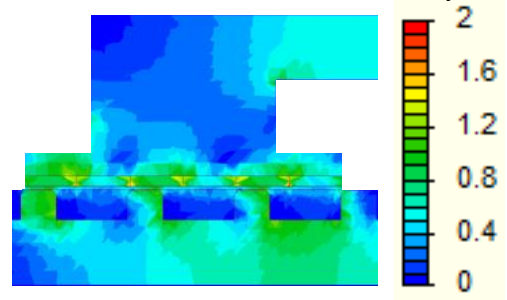

Fig. 7. Equivalence of flux density in the stator coreback for the cylindrical (a) and flat (b) topologies.

\section{General linear machines}

To design a linear machine with a constant active area over a stroke length, the stator or translator must be oversized. Ordinarily this would be the translator, and in the VHM this is a pure iron structure.

Considering any flat linear machine, the mass of the translator is a function of the axial length, $l_{a}$, the stator length, $L$, and the peak to peak amplitude of oscillation or stroke length $x$ - all defined in Fig 8 .

Equation (6) defines the amplitude ratio $X$ as the ratio of the stroke length to the stator length. 


$$
X=\frac{\mathrm{x}}{L}
$$

For a flat translator, ignoring the slots, the volume is related to its three dimensions by (7). Similarly for the stator it is defined in (8).

$$
\begin{aligned}
& v_{\text {translator }}=h_{t} L(1+X) l_{a} \\
& v_{\text {stator }}=h_{s} L l_{a}
\end{aligned}
$$

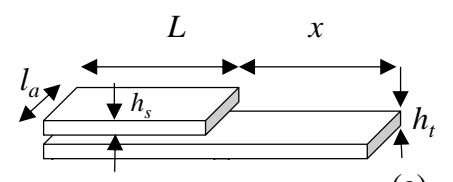

(a)

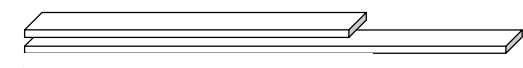

(b)

Fig. 8. (a) General linear machine dimensions, including stroke length $x$; (b) a longer stator length allows for a shorter axial length and lighter overall translator to react a fixed force.

To react a fixed force in any given topology of linear electrical machine requires a fixed active area and hence (9) can be used to relate the active and axial lengths required for a given specification.

$l_{a}=\frac{F}{\sigma L}$

Where $\sigma$ is the shear stress capability and $F$ is the specified force requirement. The machine volumes may now be given by (10) and (11).

$v_{\text {translator }}=\frac{F}{\sigma} h_{t}(1+X)$
$v_{\text {stator }}=h_{s} \frac{F}{\sigma}$

For a specific force requirement, the stator volume is hence independent of the amplitude ratio whereas the translator volume is not. For a minimum use of active material, (10) implies $X$ should be minimized, which for a fixed stroke length means L should be maximized (6). Therefore from (9), $l_{a}$ should be minimized. In summary, for linear machines delivering a fixed force with a fixed stroke length, machines with a longer active length $L$ and a shorter axial length $l_{a}$ are likely to have a lighter translator. For example, the translator of Fig. 8(b) is lighter than that of Fig. 8(a) even though active area and stroke length are the same.

\section{Mass comparison}

Fig. 9 shows the translator and stator iron volume plotted against axial length for a flat machine and a fixed rated force, derived from the simplified geometry assumptions above. The plot also shows the equivalent volume for a cylindrical machine reacting the same force. The volume of copper and magnet in both machines will be equal for each axial length.

For the flat machine, mass varies linearly with axial length $l_{a}$. For the cylindrical machine, where the airgap radius is a function of $l_{a}$, mass varies with $l_{a}^{2}$. Hence for machines with a low axial length, the cylindrical machine can offer a lower mass machine, whereas for large axial lengths the cylindrical machine mass becomes comparatively large. The plots for two values of amplitude ratio $X$ are shown, which is seen to affect the likely cross over point between the two machines.

It was argued above that lower values of $X$ and lower values of axial length give a lower translator mass, which also appears to be the area of design space where the tubular machine is most advantageous.

From this simplified geometric study and discussion, there is clearly some merit in pursuing a cylindrical VHM in terms of mass saving at some design points.

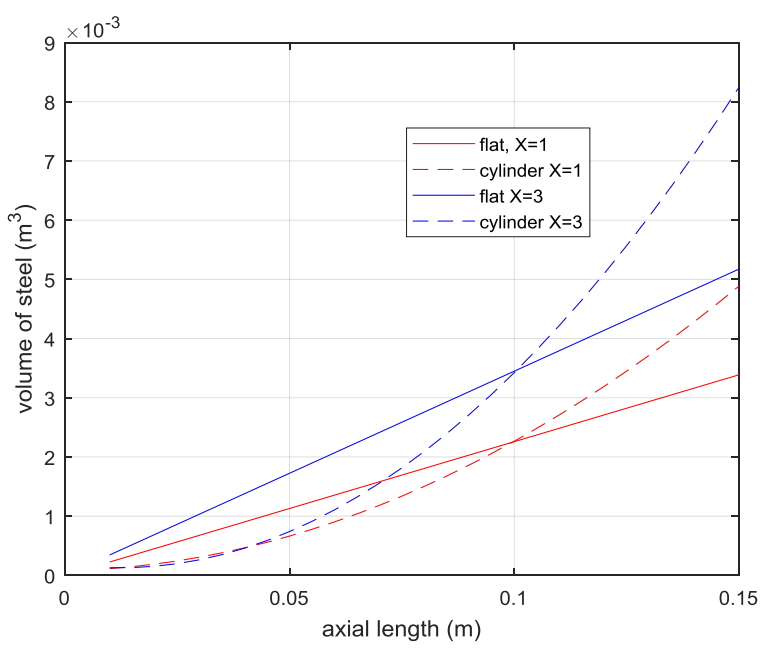

Figure 9: Comparison of steel usage in cylindrical and flat machines for a fixed force capability, fixed active area, copper mass and magnet mass. $X$ is a measure of oscillation amplitude; the amplitude ratio as defined in (6).

\section{CASE Study}

\section{A. Basic comparison}

To perform a better comparison of the two machines, a flat and cylindrical model has been designed and analyzed using Finite Element Analysis (FEA). The key model parameters held fixed between the topologies are summarized in Table II.

TABLE II. DESIGN SPECIFICATION

\begin{tabular}{cc}
\hline \hline Parameter & \\
\hline No. of PM pole per stator tooth & 6 \\
No. of coils per phase & 1 \\
No. of stator teeth per phase & 1 \\
Air gap length (mm) & 1 \\
No. of phases & 3 \\
Turns per phase & 44 \\
Stator tooth length $(\mathrm{mm})$ & 72 \\
PM width $(\mathrm{mm})$ & 12 \\
PM thickness $(\mathrm{mm})$ & 2.5 \\
PM length $(\mathrm{mm})$ & 45 \\
Translator tooth tip (mm) & 8 \\
Translator pitch $(\mathrm{mm})$ & 24 \\
\hline \hline
\end{tabular}

Fig. 10 shows the FEA model of the cylindrical machine, including the no-load magnetic flux distribution. Each stator tooth is a single phase fractional slot winding with six radially magnetized arc PMs interacting with three translator teeth. 


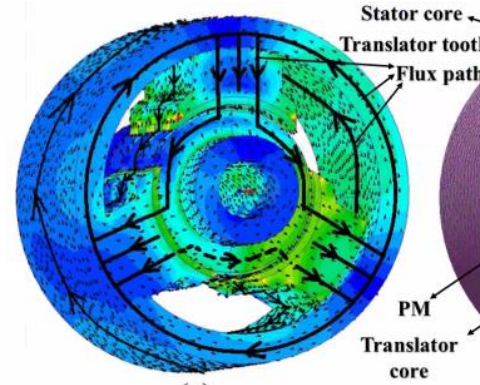

(a)

core
Fig 10. The cylindrical prototype design in 3D finite element analysis, a) magnetic flux distribution and b) 3D mesh.

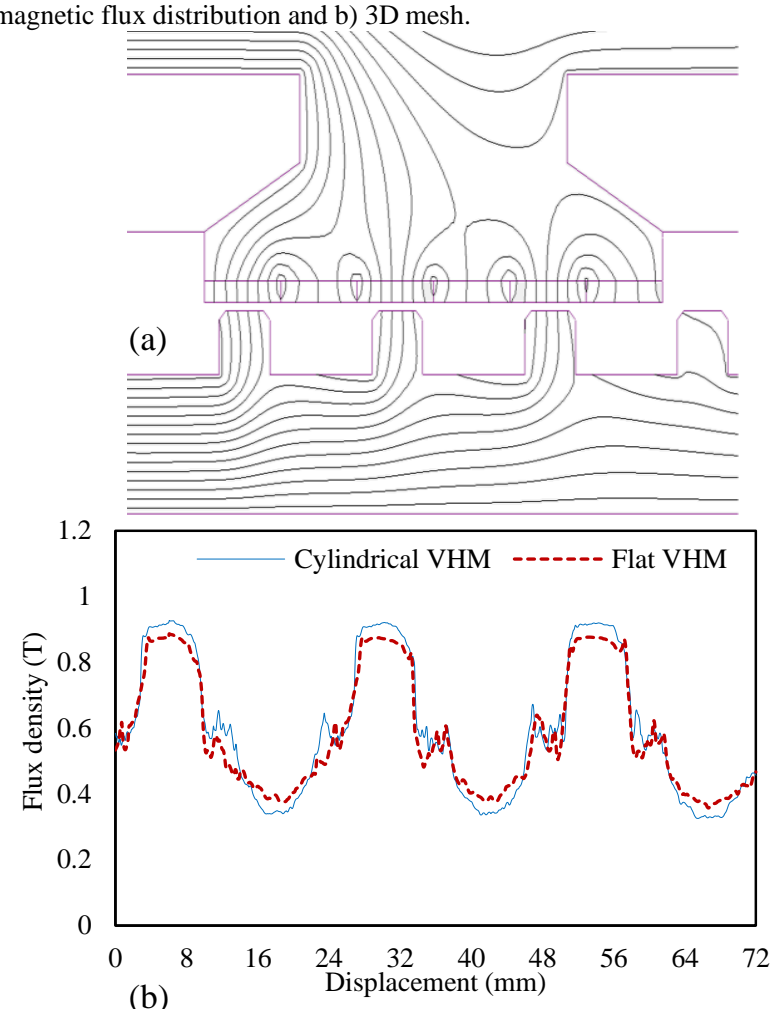

(b)

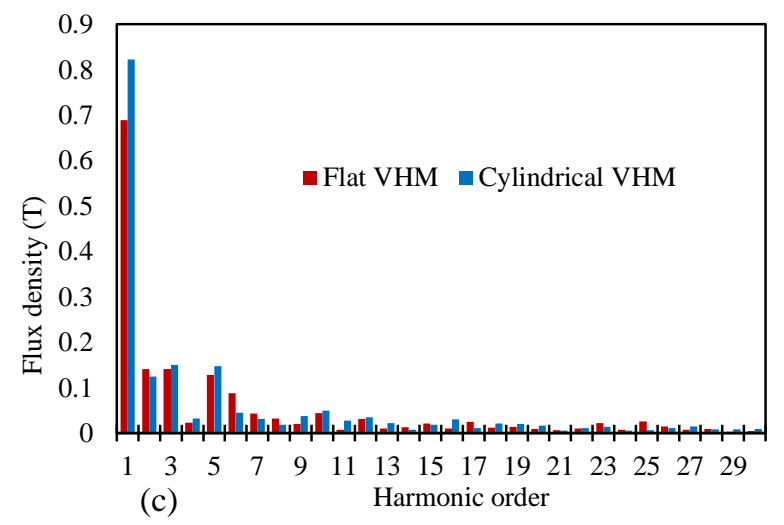

Fig. 11. a) Flux line contour for maximum flux linkage position under phase $\mathrm{A}$; b) flux density comparison under full stator tooth length during maximum flux linkage; c) flux density harmonics comparison for one translator pitch.

Fig. 11 shows a plot of the flux density under the teeth for both machines. Magnetically, the machines are very similar, with the cylindrical version having a slightly higher flux density due to the decreasing area as the flux travels radially towards the center of the translator - a 'flux focusing' type effect. Fig. 11(c) shows the flux density harmonics spectra. It can be clearly seen that the higher order harmonics are similar due to the similar nature of interaction of flux between stator PM and translator. The fundamental harmonic, which contributes to the force production, is higher in the cylindrical VHM.

\section{B. Performance}

Both machines have undergone a design study to minimize active material and maximize force production. The final designs deviate slightly from the simple geometry described in section $I V$. The two machines were shown in Fig 1, and have, for example, thinner core-backs and shaped stator teeth for performance improvement and mass reduction. Some of the key machine variables are shown in Table III. The ratio of active area to machine volume is higher in the cylindrical machine.

\begin{tabular}{|c|c|c|}
\hline Parameter & Flat VHM & $\begin{array}{l}\text { Cylindrical } \\
\text { VHM }\end{array}$ \\
\hline PM mass (kg) & 0.18 & 0.18 \\
\hline Stator core mass $(\mathrm{kg})$ & 1.38 & 1.06 \\
\hline Stator teeth mass $(\mathrm{kg})$ & 1.3 & 1 \\
\hline $\begin{array}{l}\text { Stator core thickness } \\
(\mathrm{mm})\end{array}$ & 16 & 8 \\
\hline Active Translator teeth & 9 & 4 \\
\hline $\begin{array}{l}\text { Active translator core } \\
\text { mass }(\mathrm{kg})\end{array}$ & 1.6 & 0.4 \\
\hline $\begin{array}{l}\text { Active translator teeth } \\
\text { mass }(\mathrm{kg})\end{array}$ & 0.18 & 0.35 \\
\hline $\begin{array}{l}\text { Translator core } \\
\text { thickness }(\mathrm{mm})\end{array}$ & 15 & 5 \\
\hline $\begin{array}{l}\text { Active air gap area } \\
\qquad\left(\mathrm{mm}^{2}\right)\end{array}$ & 12600 & 15758 \\
\hline $\begin{array}{l}\text { Active machine } \\
\text { volume }\left(\mathrm{mm}^{3}\right)\end{array}$ & 836010 & 776578 \\
\hline $\begin{array}{l}\text { Active machine length } \\
\qquad(\mathrm{mm})\end{array}$ & 280 & 88 \\
\hline
\end{tabular}

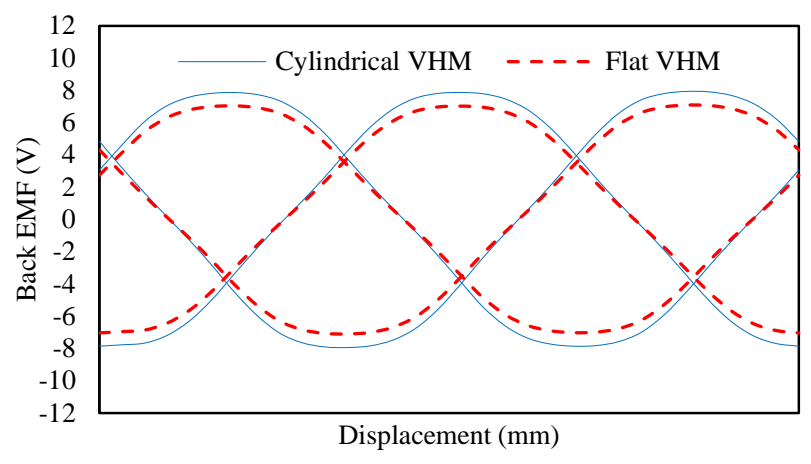

Fig.12. Simulated back emf at $1.2 \mathrm{~m} / \mathrm{s}$

Fig. 12 presents the no load back EMF waveform of the cylindrical and flat VHM at the nominal speed of $1.2 \mathrm{~m} / \mathrm{s}$. The cylindrical machine has a higher amplitude of back EMF, clarified by the higher first order harmonic shown in Fig. 13. This is a direct result of the higher flux density resulting from the flux focusing effect of the cylindrical machine. 


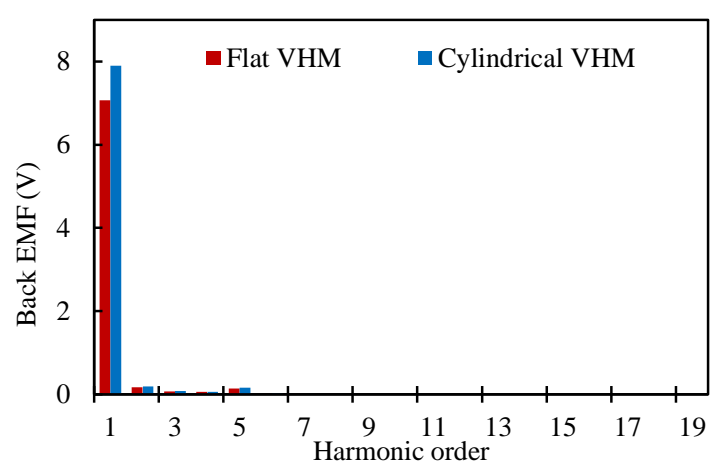

Fig.13. Harmonic breakdown of simulated back emf

The cogging force at zero current is illustrated in Fig. 14 which shows there are three cogging cycles per electrical cycle. Fig 15 shows the force produced by a sinusoidal current injected into the $\mathrm{q}$ axis. The average thrust force of the cylindrical model is $194 \mathrm{~N}$ compared to $172 \mathrm{~N}$ for the flat model with a rated armature RMS current of $14.8 \mathrm{~A}$. The percentage increase in force of the cylindrical version is equal to the percentage increase in back EMF.

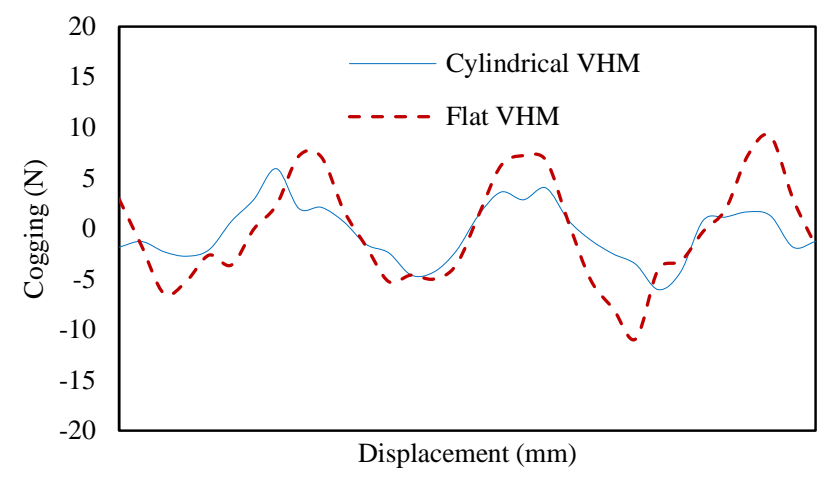

Fig.14. Simulated cogging force

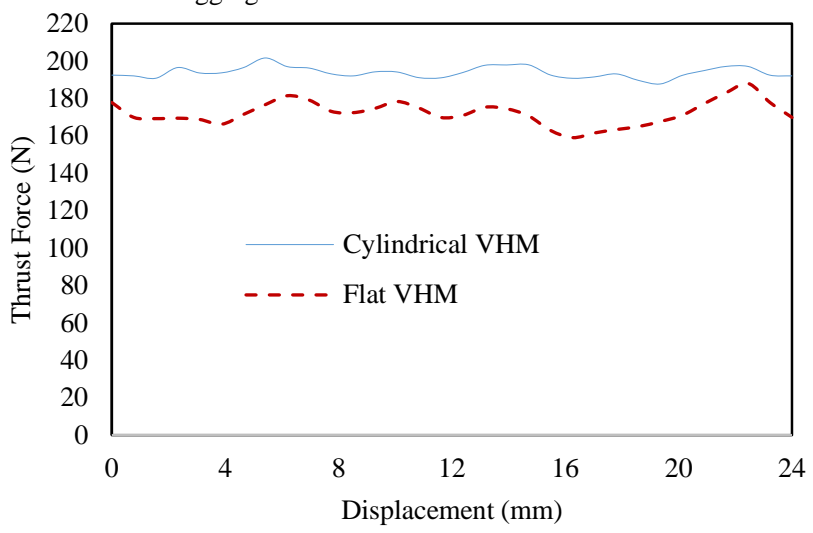

Fig.15. Simulated rated thrust force comparison

\section{Comparison}

Machine constant power density, $K$, as defined in (12), can be used to compare machines of this type, see for example [20]. $K$ is defined as the machine constant $K_{G}$ of (13) divided by the active machine volume.

$K=\frac{K_{G}}{V}=\frac{F}{V \sqrt{W_{c}}} \propto \frac{F}{V}$
$K_{G}=\frac{F}{\sqrt{W_{c}}}=\frac{F}{\sqrt{m I^{2} R}}$

Where $w_{c}$ is the copper loss, $I$ is the RMS armature current, $m$ is the number of phases, $R$ is the winding resistance per phase and $V$ is the active volume of the machine.

TABLE IV. SiMULATED PERFORMANCE OF BOTH TOPOLOGIES.

\begin{tabular}{ccc}
\hline \hline Parameter & $\begin{array}{c}\text { Flat } \\
\text { VHM }\end{array}$ & Cylindrical VHM \\
\hline Thrust force $(\mathrm{N})$ & 172 & 194 \\
Thrust ripple $(\mathrm{N})$ & 26 & 14 \\
Cogging $(\mathrm{N})$ & 34 & 20 \\
Back EMF $(\mathrm{V})$ & 7 & 7.9 \\
Flux linkage $(\mathrm{mWb})$ & 21.8 & 24.6 \\
$\begin{array}{c}\text { Shear stress }\left(\mathrm{kN} / \mathrm{m}^{2}\right) \\
\text { Machine constant }\end{array}$ & 13.7 & 12.3 \\
density $\left(\mathrm{kN} / \sqrt{\mathrm{W}} \mathrm{m}^{3}\right)$ & 25.5 & 31.0 \\
\hline \hline
\end{tabular}

For both flat and cylindrical machines, the coil area, winding resistance per phase and RMS armature current applied are constant. Machine constant power density is therefore proportional to the output force and inversely proportional to the active volume of the machine, (12). Table IV compares the predicted machine performance and machine constant for the two topologies. The cylindrical model gives a higher machine constant due to its lower active volume and increased force capability.

Power factor is a known issue with this family of machines, and it will likely be affected by the move from a flat to a cylindrical cross-section. Analysis here has assumed the machine is operated at constant speed, and when loaded the current is controlled to be in phase with the back emf. Ignoring any saturation effects, the operating power factor is equal to the ratio of open circuit back emf to loaded terminal voltage. At the rated speed of $1.2 \mathrm{~m} / \mathrm{s}$ it was shown earlier that the cylindrical machine had a higher back emf, with the open circuit RMS voltage being $12 \%$ greater. Terminal voltage, as calculated by FEA, differs by less than $2 \%$ and so the increase in back emf translates directly into an increase in the power factor. The baseline flat machine has a power factor of 0.39 , whereas the cylindrical machine operates at a power factor of 0.44 . Whilst the authors accept this is still a low value, the adoption of a cylindrical topology for linear variants represents a meaningful improvement in power factor which could equally be applied to other variants of the Vernier Hybrid Machine that exhibit a better power factor such as [10]. 


\section{PROTOTYPE BUILDING \& TESTING}

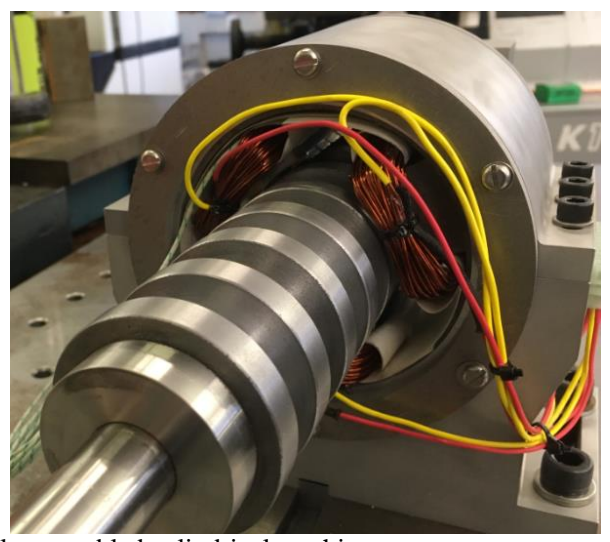

Fig. 16. Fully assembled cylindrical machine

A prototype cylindrical machine has been designed and built to prove the concept and validate the FEA. The flux flow is in the radial, axial and circumferential direction and so the entire machine is made from soft magnetic composite (SMC). The translator and stator have been wire eroded from solid prototyping SMC material. Fig 16 shows the fully assembled machine, where the arc magnets are glued to the teeth and the 44 turns per coils have been manually wound.

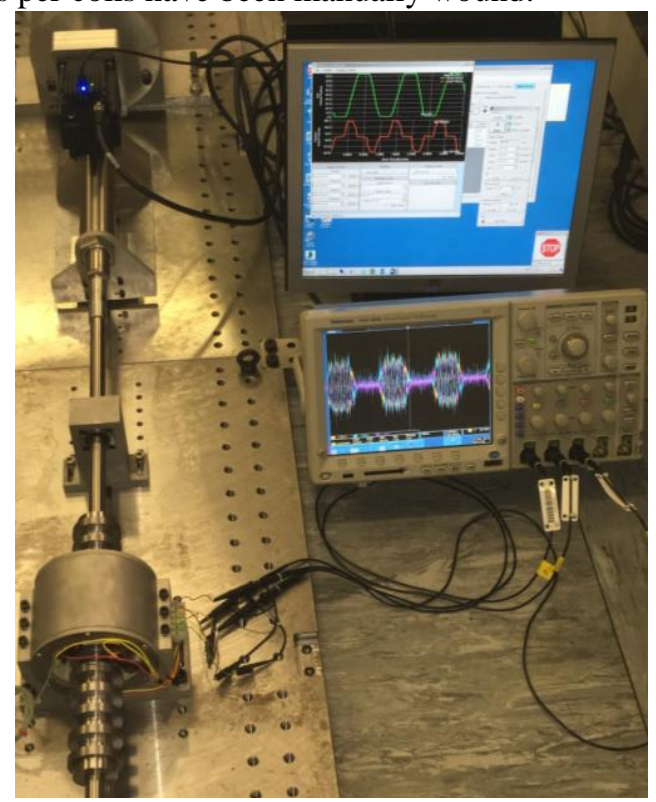

Fig. 17. Cylindrical machine being tested

The machine has been tested by being driven open circuit by a ball screw over a $100 \mathrm{~mm}$ displacement with a peak speed of just over $1 \mathrm{~m} / \mathrm{s}$, Fig. 17. Fig. 18 shows the results of one mechanical cycle and a comparison between the simulation and measured results over 2 electrical cycles.

In simulation, the variation in rms emf across the three phases is less than $2 \%$. In the measured values, there is a maximum variation of $26 \%$, with rms values of $1,0.73$ and 0.83 per unit. This is thought to be due to the translator not being exactly concentric in the stator - meaning each phase of the prototype has a different magnetic airgap, and the value of that airgap is not constant with angular position. Air gap size across the three teeth of the prototype was measured at various points in the airgap and throughout the oscillation cycle and found to vary between $0.6 \mathrm{~mm}$ and $1.1 \mathrm{~mm}$. The variation is clearly visible in Fig. 19.
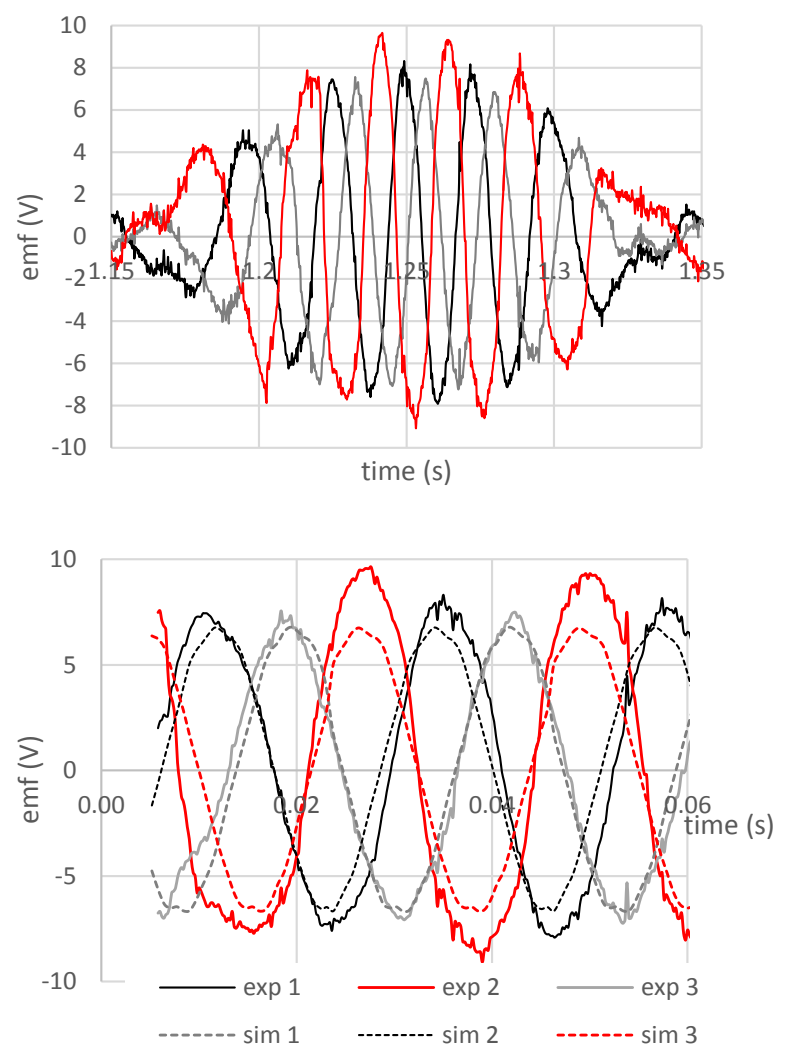

Fig. 18. Measured emf, for single mechanical stroke (upper) and (lower) compared with ideal simulation over two electrical cycles

The FEA model was adapted to allow for a non-concentric stator. It was offset with respect to the center line of phase A by $+/-0.4 \mathrm{~mm}$ giving a variation in the average airgap across the three teeth of $0.7-1.3 \mathrm{~mm}$, as shown in Table V.
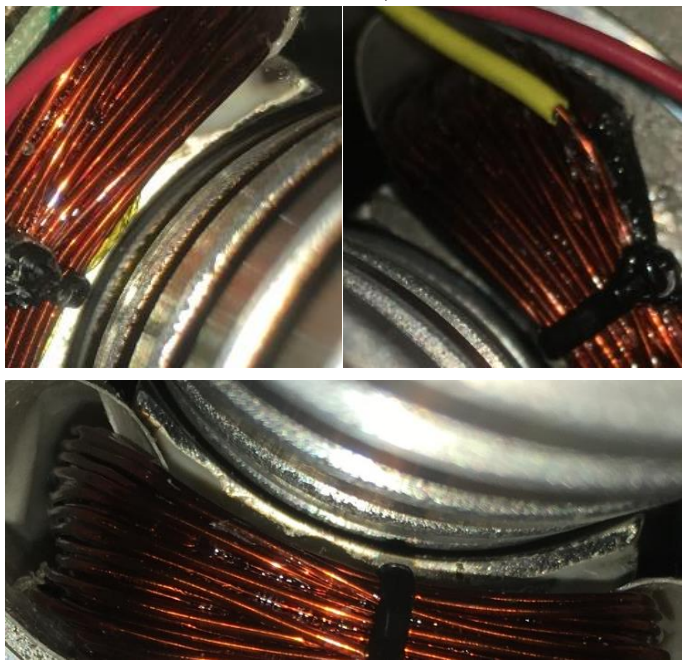

Fig. 19. The three airgap regions of the prototype.

Table V shows a summary of the simulation and experimental results. The offset of the prototype translator is likely not along the center line of a tooth, and so none of the simulations in Table $\mathrm{V}$ is fully representative of the real situation. 
TEC-00995-2017

TABLE V. SiMULATED AND MEASURED PERFORMANCE.

\begin{tabular}{|c|c|c|c|c|c|}
\hline & & \multicolumn{3}{|c|}{ simulated } & \multirow{2}{*}{$\frac{\text { measured }}{--}$} \\
\hline offset & $\mathrm{mm}$ & 0.40 & 0.00 & -0.40 & \\
\hline $\begin{array}{l}\text { air gap } \\
\text { phase A }\end{array}$ & $\mathrm{mm}$ & 0.70 & 1.00 & 1.30 & $0.6-1.1$ \\
\hline $\begin{array}{l}\text { air gap } \\
\text { phase B }\end{array}$ & $\mathrm{mm}$ & 1.20 & 1.00 & 0.90 & $0.6-1.1$ \\
\hline $\begin{array}{l}\text { air gap } \\
\text { phase } C\end{array}$ & $\mathrm{~mm}$ & 1.20 & 1.00 & 0.90 & $0.6-1.1$ \\
\hline $\begin{array}{c}\text { RMS emf } \\
\text { B/A }\end{array}$ & $\begin{array}{l}\text { per } \\
\text { unit }\end{array}$ & 0.86 & 1.02 & 1.21 & 0.73 \\
\hline $\begin{array}{c}\text { RMS emf } \\
\text { C/A }\end{array}$ & $\begin{array}{l}\text { per } \\
\text { unit }\end{array}$ & 0.83 & 0.99 & 1.17 & 0.83 \\
\hline $\begin{array}{l}\text { Peak emf } \\
\text { Phase A }\end{array}$ & $\mathrm{V}$ & 9.63 & 7.05 & 6.31 & 9.64 \\
\hline $\begin{array}{c}\text { Peak emf } \\
\text { phase B }\end{array}$ & V & 8.17 & 6.97 & 7.34 & 8.32 \\
\hline $\begin{array}{l}\text { Peak emf } \\
\text { phase C }\end{array}$ & V & 8.18 & 7.01 & 7.45 & 7.56 \\
\hline \multicolumn{2}{|c|}{$\begin{array}{c}\text { Error in peak } \\
\text { emf simulation } \\
\text { phase } \mathrm{A}\end{array}$} & $0 \%$ & $27 \%$ & $35 \%$ & \\
\hline \multicolumn{2}{|c|}{$\begin{array}{c}\text { Error in peak } \\
\text { emf simulation } \\
\text { phase } \mathrm{B}\end{array}$} & $2 \%$ & $16 \%$ & $12 \%$ & \\
\hline \multicolumn{2}{|c|}{$\begin{array}{c}\text { Error in peak } \\
\text { emf simulation } \\
\text { phase } \mathrm{C}\end{array}$} & $-8 \%$ & $7 \%$ & $1 \%$ & \\
\hline
\end{tabular}

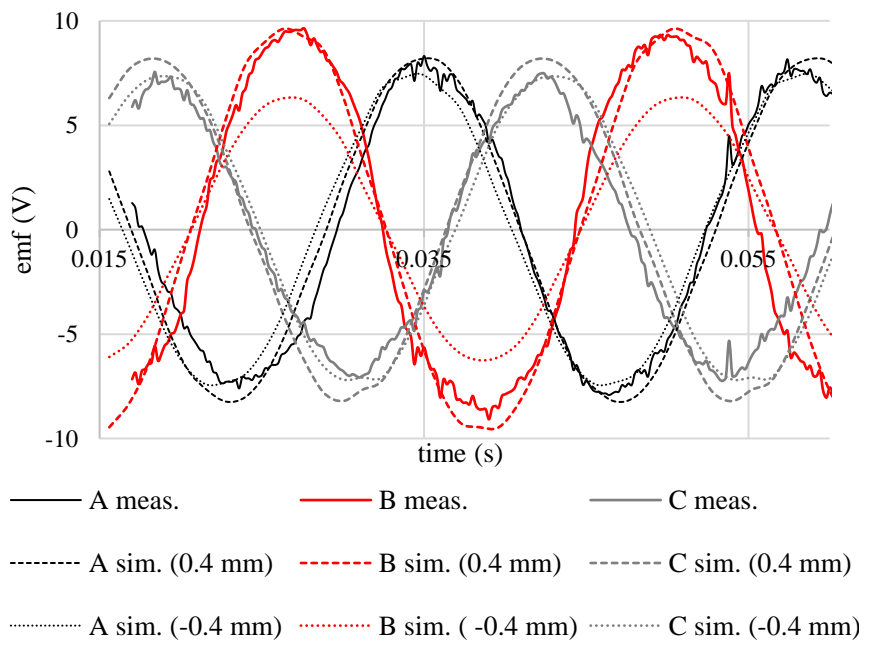

Fig. 20. Measured (meas.) and simulated (sim.) results for two values of offset translator

The $+0.4 \mathrm{~mm}$ offset result gives the closest result to the measured emf value (8\% error) and also represents the closest approximation to the measured airgap. A direct comparison of the offset simulation and the experimental results is shown in Fig 20.

\section{CONCLUSION}

A cylindrical version of a linear surface mounted PM Vernier Hybrid Machine has been introduced. A basic geometrical study has been used to show it can offer a mass saving in some scenarios compared to a single sided flat topology. A more thorough design study based on FEA has indicated that the cylindrical version can offer a $20 \%$ improvement in the machine constant density and a $12 \%$ improvement in operating power factor. The improved performance is primarily due to the flux focusing effect of the cylindrical version increasing the flux density in the airgap combined with an improved airgap area to volume ratio.

Finally the cylindrical topology has been built and demonstrated in a laboratory, where a measured imbalance in the back emf across the three phases of $14-17 \%$ is believed to be due to an offset translator. Simulations could replicate experimental results to within $8 \%$.

\section{REFERENCES}

[1] M. A. Mueller and N. J. Baker, "Modelling the performance of the vernier hybrid machine," IEE Proc. Elect. Power Appl., vol. 150, no. 6, pp. 647-654, 2003.

[2] M. A. H. Raihan, N. J. Baker, K. J. Smith, and A. A. Almoraya, "Investigation of a doubly salient Halbach array linear permanent magnet machine for wave energy converters," in Electrical Machines and Systems (ICEMS), 2017 20th International Conference on, 2017, pp. 1-5: IEEE.

[3] E. Spooner and L. Haydock, "Vernier hybrid machines," IEE Proc. Elect. Power Appl., vol. 150, no. 6, pp. 655-662, 2003.

[4] G. Xu, G. Liu, M. Chen, X. Du, and M. Xu, "Costeffective vernier permanent-magnet machine with high torque performance," IEEE Trans. Magn., vol. 53, no. 11, pp. 1-4, 2017.

[5] Y. Du, M. Cheng, K. T. Chau, X. Liu, F. Xiao, and W. Zhao, "Linear primary permanent magnet vernier machine for wave energy conversion," IET Elect. Power Appl., vol. 9, no. 3, pp. 203-212, 2015.

[6] Y. Du et al., "Comparison of linear primary permanent magnet vernier machine and linear vernier hybrid machine," IEEE Trans. Magn., vol. 50, no. 11, pp. 1-4, 2014.

[7] G. Liu, L. Ding, W. Zhao, Q. Chen, and S. Jiang, "Nonlinear Equivalent Magnetic Network of a Linear Permanent Magnet Vernier Machine With End Effect Consideration," IEEE Trans. Magn., vol. 54, no. 1, pp. 1-9, 2018.

Y. Yang, G. Liu, X. Yang, and X. Wang, "Analytical Electromagnetic Performance Calculation of Vernier Hybrid Permanent Magnet Machine," IEEE Trans. Magn., 2018.

[9] O. Farrok, M. R. Islam, M. R. I. Sheikh, Y. Guo, and J. Zhu, "A Split Translator Secondary Stator Permanent Magnet Linear Generator for Oceanic Wave Energy Conversion," IEEE Trans. Ind. Electron., 2017.

[10] T. Ching, K. Chau, and W. Li, "Power factor improvement of a linear vernier permanent-magnet machine using auxiliary DC field excitation," IEEE Trans. Magn., vol. 52, no. 7, pp. 1-4, 2016. 
TEC-00995-2017

[11] A. A. Almoraya, N. J. Baker, K. J. Smith, and M. A. H. Raihan, "Development of a double-sided consequent pole linear vernier hybrid permanentmagnet machine for wave energy converters," in IEEE Int. Electric Machines and Drives Conf. (IEMDC) 2017, pp. 1-7.

[12] H. Polinder, M. E. C. Damen, and F. Gardner, "Linear PM generator system for wave energy conversion in the AWS," IEEE Trans. Energy Convers., vol. 19, no. 3, pp. 583-589, 2004.

[13] M. Leijon et al., "Multiphysics simulation of wave energy to electric energy conversion by permanent magnet linear generator," IEEE Trans. Energy Convers., vol. 20, no. 1, pp. 219-224, 2005.

[14] W. Li, K. T. Chau, and J. Z. Jiang, "Application of linear magnetic gears for pseudo-direct-drive oceanic wave energy harvesting," IEEE Trans. Magn., vol. 47, no. 10, pp. 2624-2627, 2011.

[15] H. Weh, "Design of an integrated propulsion, guidance, and levitation system by magnetically excited transverse flux linear motor (TFM-LM)," IEEE Trans. Energy Convers., vol. 19, no. 3, pp. 477484, 2004.

[16] H. Polinder, B. C. Mecrow, A. G. Jack, P. G. Dickinson, and M. A. Mueller, "Conventional and TFPM linear generators for direct-drive wave energy conversion," IEEE Trans. Energy Convers., vol. 20, no. 2, pp. 260-267, 2005.

[17] A. W. van Zyl, C. G. Jeans, R. J. Cruise, and C. F. Landy, "Comparison of force to weight ratios between a single-sided linear synchronous motor and a tubular linear synchronous motor," in Electric Machines and Drives, 1999. International Conference IEMD'99, 1999, pp. 571-573: IEEE.

[18] M. A. H. Raihan, N. J. Baker, K. J. Smith, and A. A. Almoraya, "An E-core linear veriner hybrid permanent magnet machine with segmented translator for direct drive wave energy converter," in IEEE Int. Electric Machines and Drives Conf. (IEMDC) 2017, pp. 1-6: IEEE.

[19] N. J. Baker, "Linear generators for direct drive marine renewable energy converters," Durham University, 2003.

[20] N. Iwabuchi, A. Kawahara, T. Kume, T. Kabashima, and N. Nagasaka, "A novel high-torque reluctance motor with rare-earth magnet," IEEE Trans. Ind. Appl., vol. 30, no. 3, pp. 609-614, 1994. 